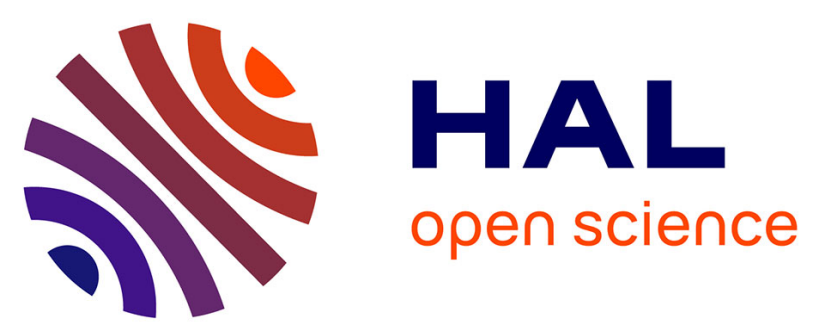

\title{
Integration of control loops in coupled field circuit model to study magnetic devices supplied by power electronic converter and their control
}

\author{
Gilbert Manot, Yvan Lefèvre, Hubert Piquet, Frédéric Richardeau
}

\section{- To cite this version:}

Gilbert Manot, Yvan Lefèvre, Hubert Piquet, Frédéric Richardeau. Integration of control loops in coupled field circuit model to study magnetic devices supplied by power electronic converter and their control. COMPEL: The International Journal for Computation and Mathematics in Electrical and Electronic Engineering, 2002, vol. 21 ( $\mathrm{n}^{\circ} 4$ ), pp. 563-572. 10.1108/03321640210437815 . hal01664831

\section{HAL Id: hal-01664831 \\ https://hal.science/hal-01664831}

Submitted on 15 Dec 2017

HAL is a multi-disciplinary open access archive for the deposit and dissemination of scientific research documents, whether they are published or not. The documents may come from teaching and research institutions in France or abroad, or from public or private research centers.
L'archive ouverte pluridisciplinaire HAL, est destinée au dépôt et à la diffusion de documents scientifiques de niveau recherche, publiés ou non, émanant des établissements d'enseignement et de recherche français ou étrangers, des laboratoires publics ou privés. 


\section{OATAO \\ Open Archive Toulouse Archive Ouverte}

Open Archive TOULOUSE Archive Ouverte (OATAO)

OATAO is an open access repository that collects the work of Toulouse researchers and makes it freely available over the web where possible.

This is an author-deposited version published in :

http://oatao.univ-toulouse.fr/

Eprints ID : 19305

To link to this article : DOI:10.1108/03321640210437815

URL : https://doi.org/10.1108/03321640210437815

To cite this version : Manot, Gilbert $\stackrel{5}{\varpi}$ and Lefèvre, Yvan Piquet, Hubert $\leftrightarrows$ and Richardeau, Frédéric control loops in coupled field circuit model to study magnetic devices supplied by power electronic converter and their control. (2002) COMPEL : The International Journal for Computation and Mathematics in Electrical and Electronic Engineering, vol. $21\left(\mathrm{n}^{\circ}\right.$ 4). pp. 563-572. ISSN 0332-1649

Any correspondence concerning this service should be sent to the repository administrator: staff-oatao@listes-diff.inp-toulouse.fr 


\title{
Integration of control loops in coupled field circuit model to study magnetic devices supplied by power electronic converter and their control
}

\author{
G. Manot, Y. Lefèvre, H. Piquet and F. Richardeau \\ Laboratoire d'Electrotechnique et d'Electronique Industrielle, \\ Unité Mixte de Recherche INPT-ENSEEIHT/CNRS, \\ Toulouse France
}

Keywords Modelling, Magnetic fields, Control

Abstract In this paper, we present a method to take into account the feedback control in software developed from coupled field circuit models. The implementation of control loops is done in a software which is able to simulate electromagnetic devices associated with power electronic circuits having a time dependent topology. The control strategy is implemented in a discrete-time version and can manage all controllable electronic switches by means of different electric or magnetic quantities calculated during the simulation (flux, currents, voltages,...). Electrical systems involving magnetic devices, power electronic converters and their control devices can be simulated in presence of phenomena such as eddy currents or saturation of the magnetic materials.

\section{Introduction}

Many works have been dealt with field circuit coupled models (Tsukerman et al., 1993; Piriou and Razek, 1993; Lombard and Meunier, 1993). Nowadays, time stepped finite element methods are very often used in industrial applications where power electronic converters are associated with magnetic devices (Charpentier et al., 1997). In many software based on time stepped coupled field circuit model, the switching control signals of power electronic components (PECs), like transistors or thyristors, are defined in an open loop manner at the beginning of the simulation (Sadowski et al., 1993). In order to deal with industrial applications involving feedback control operations, the method of control loops has been developed first for power electronic circuit models (Louisnard et al., 1992) then for coupled field circuit models (Kuo-Peng et al., 1998). In this paper, we present an application of this method to model an induction heating device constituted of a hollow cylinder made of ferromagnetic conducting material and a coil made of ten solid conductors. It is supplied by a resonant converter. Considering the working frequency, eddy 
currents in conductors can not be neglected. First, we sum up the coupled field circuit model. Then, the method to take into account feedback control is presented.

\section{Coupled field circuit model}

If displacement currents can be neglected, the magnetic field is governed by (Tsukerman et al., 1993):

$$
\operatorname{curl} \nu \text { curla }=j=\sigma \mathrm{\partial}_{t} a-\sigma \operatorname{grad}(\phi)
$$

where $j$ is the current density, $\nu$ the reluctivity and $\sigma$ the conductivity of media. Assuming a 2D transverse magnetic field problem, the gradient of the electric scalar potential is related to the potential difference $u_{\text {so }}$ between the ends of the conductor and the current in a solid conductor can be related to the vector potential $\mathbf{a}$ and the potential difference $u_{\text {so }}$

$$
\begin{gathered}
(\operatorname{grad} \phi)_{z}=\frac{u_{\mathrm{s} O}}{L} \\
i_{\mathrm{so}}=g_{\mathrm{so}} u_{\mathrm{so}}+\iint_{\mathrm{SO}} \sigma \partial_{t} \mathrm{a} \mathrm{d} s
\end{gathered}
$$

where $L$ is the axial length of the system and $g_{\text {so }}$ the conductance of the solid conductor. After discretisation of the study domain, with finite elements, we obtain the following system of differential equations

$$
\begin{gathered}
M A+N \frac{\mathrm{d}}{\mathrm{d} t} A+\boldsymbol{P}_{\mathrm{so}} \boldsymbol{U}_{\mathrm{so}}=0 \\
\boldsymbol{G}_{\mathrm{so}} \boldsymbol{U}_{\mathrm{so}}+\boldsymbol{Q} \frac{\mathrm{d}}{\mathrm{d} t} \mathrm{~A}-\boldsymbol{I}_{\mathrm{so}}=0
\end{gathered}
$$

where A represents the axial component of the magnetic potential vector on the nodes of the mesh, $\boldsymbol{U}_{\mathrm{so}}$ the potential differences and $\boldsymbol{I}_{\mathrm{so}}$ the currents through solid conductors. Expressing that solid conductors are in series in the windings of the magnetic device, we obtain the following matrix relations

$$
\begin{aligned}
& \sum \boldsymbol{U}_{\mathrm{so}}-\boldsymbol{U}_{\mathrm{w}}=0 \\
& \boldsymbol{I}_{\mathrm{s} 0}-\sum^{\mathrm{T}} \boldsymbol{I}_{\mathrm{w}}=0
\end{aligned}
$$

where $\boldsymbol{U}_{\mathrm{w}}$ represents the voltage drops on windings, $\boldsymbol{I}_{\mathrm{w}}$ the currents across them. $\Sigma$ sums the voltage drops on solid conductor belonging to the same winding. 
From the Kirshhoff voltage law, the Kirshhoff current law and a tree given by the Welsh algorithm, the circuit equations can be put in the state form (Charpentier et al., 1997):

$$
\frac{\mathrm{d}}{\mathrm{d} t} \boldsymbol{X}_{\mathrm{c}}=\boldsymbol{\alpha} \boldsymbol{X}_{\mathrm{c}}+\boldsymbol{\beta}_{\mathrm{w}} \boldsymbol{U}_{\mathrm{w}}+\boldsymbol{\beta} \boldsymbol{U}+\boldsymbol{\gamma} \frac{\mathrm{d}}{\mathrm{d} t} \boldsymbol{U}
$$

where $X_{\mathrm{C}}$ represents the state variables which are the voltage drops on capacitors in the tree branch and the currents across inductors in the links, $U$ the vector of the real current and voltage sources of the circuit, $\boldsymbol{U}_{\mathrm{w}}$, as in equation (6), the voltage drops across the windings of the magnetic device. The currents in the windings are function of the state variables and the real sources:

$$
I_{\mathrm{w}}=F_{\mathrm{w}} X_{\mathrm{c}}+\boldsymbol{G}_{\mathrm{w}} \boldsymbol{U}
$$

Equations (4) and (8) can be linked together using relations (5)-(7) and (9):

$$
\begin{gathered}
\boldsymbol{M} \boldsymbol{A}+\boldsymbol{N} \frac{\mathrm{d}}{\mathrm{d} t} \boldsymbol{A}+\boldsymbol{P}_{\mathrm{so}} \boldsymbol{U}_{\mathrm{so}}=0 \\
\boldsymbol{G}_{\mathrm{so}} \boldsymbol{U}_{\mathrm{so}}+\boldsymbol{Q} \frac{\mathrm{d}}{\mathrm{d} t} \boldsymbol{A}-\sum{ }^{\mathrm{T}} \boldsymbol{F}_{\mathrm{w}} \boldsymbol{X}_{\mathrm{c}}=\sum{ }^{\mathrm{T}} \boldsymbol{G}_{\mathrm{W}} \boldsymbol{U} \\
\frac{\mathrm{d}}{\mathrm{d} t} \boldsymbol{X}_{\mathrm{c}}-\alpha \boldsymbol{X}_{\mathrm{c}}-\boldsymbol{\beta}_{\mathrm{w}} \sum \boldsymbol{U}_{\mathrm{s} O}=\boldsymbol{\beta} \boldsymbol{U}+\boldsymbol{\gamma} \frac{\mathrm{d}}{\mathrm{d} t} \boldsymbol{U}
\end{gathered}
$$

This global system of equations are solved by a step by step method knowing the real sources $\boldsymbol{U}$ to obtain the potential vector on each node of the mesh $(A)$, the voltage drops on solid conductors $\left(\boldsymbol{U}_{\mathrm{so}}\right)$ and the state variables $\left(X_{\mathrm{c}}\right)$.

The (PECs) like diodes, transistors or thyristors are modelled as two values resistances: a very high resistance when it is off and a very low one when on. The states of the PECs are not known a priori. Their states are managed by a coloured Petri net representation (Charpentier et al., 1997). Up to this point, to simulate the dynamic operation of the whole system, the control signals of PECs are defined all for once at the beginning of the simulation (Sadowski et al., 1993).

\section{Taking into account of feedback control}

In order to take into account the feedback control, we have implemented the method of control loops in the software developed from the coupled field circuit model (Louisnard et al., 1992; Kuo-Peng et al., 1998). We have adopted a formalism intimately related to the sampled control model. The method consists to interrupt the main program every sampling time. Communications between the coupled system and the control block occurs only at these 
sampling moments. This operation is illustrated by the diagram shown on Figure 1. Precisely at each sampling moments the control block receives its inputs sent by the main program. These inputs are defined as voltage drops across resistors placed in the circuit. The subroutine computes the internal variables to elaborate the control laws and sends back to the main program the gating orders of the PEC. From this model, a software called MagCvs has been elaborated. As the main program, the code for the controls law is written by the user in FORTRAN. It can also be written in C. The implantation of this control mode is inserted in the simulation model according to the Nassi and Scheidermann graph given in Figure 2.

\section{Application to the study of an induction heating device}

We present studies, made by means of this model, of an experimental induction heating device used for education and research purposes. Plate 1 shows a photography of this device while operating. The piece of material to be heated is made up of a hollow ferromagnetic cylinder with a length of $290 \mathrm{~mm}$ and a

re 1.

od of sampling taking into account ack control re 2.

Nassi and

idermann graph of ontrol block in the ation model

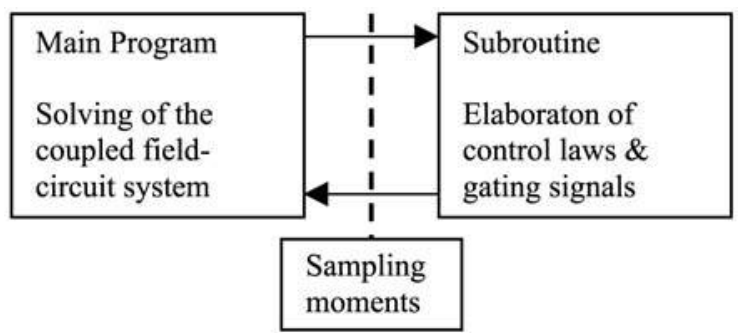

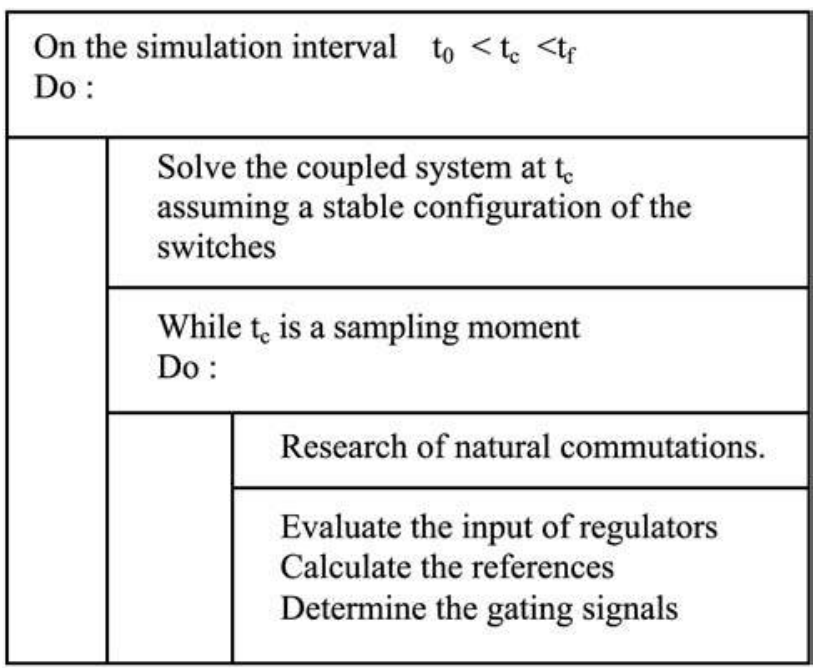




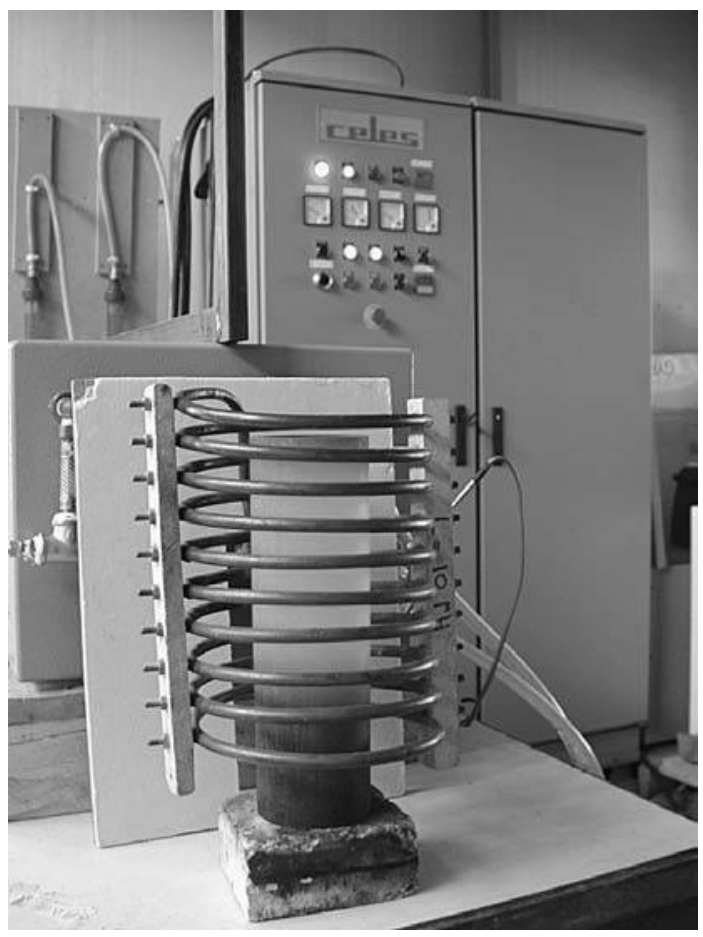

Plate experimental de

thickness of $10 \mathrm{~mm}$. The inductor is a coil made of ten turns of copper helical round conductor of $8 \mathrm{~mm}$ inner diameter and $10 \mathrm{~mm}$ outer diameter.

The magnetic device can be assumed axisymmetric and the coil can be modelled by ten solid conductors connected in series and spaced equally around the ferromagnetic cylinder. Taking into account all the geometrical symmetries, only half of the axisymmetrical domain is considered. Therefore, the study domain contains only half of the cylinder and only five conductors of the coil. Figure 3 shows the mesh of the heart of the study domain. The conductivity and the relative permeability of the copper inductor are respectively, $5.6 \times 10^{7} \mathrm{~S} / \mathrm{m}$ and 1 . The conductivity of the ferromagnetic cylinder, which is made with steel, is $4.10^{6} \mathrm{~S} / \mathrm{m}$ at room temperature.

First, we studied the response frequency of the inductor formed by the ferromagnetic cylinder and the coil. This study has been made by simulations and experiments. Experimental measurements were made by an inductance analyser of WAYNE KERR. This analyser is able to measure the impedance of an inductor for a large range of frequency from $20 \mathrm{~Hz}$ to $100 \mathrm{kHz}$. Simulations were made with a complex version of MagCvs solving the global system in equation (10) by replacing the time derivative by the complex number $j \omega$ where $\omega$ is the pulsation of the sinusoidal voltage $\boldsymbol{U}$ applied on the 


\section{re 3.}

element meshing heart of study in

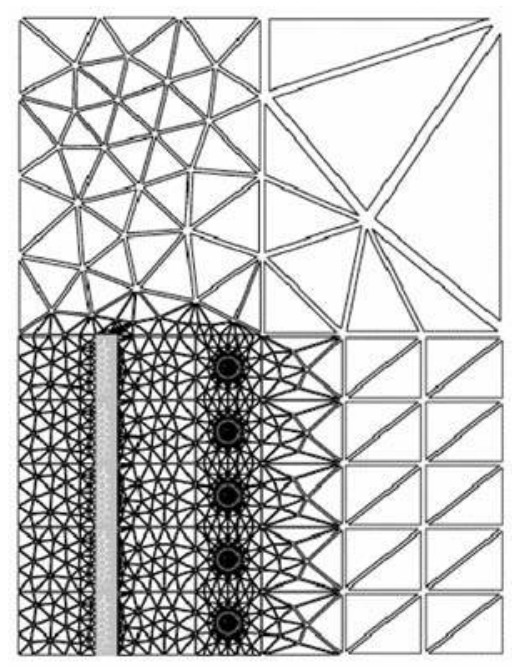

coil (Lombard and Meunier, 1993). From the current $I_{\mathrm{w}}$ in the coil obtained by simulations, we can deduce the series resistance $R_{\mathrm{s}}$ and the series inductance $L_{\mathrm{s}}$ of the inductor in function of the frequency of the input voltage. We have considered several values of the relative permeability of the cylinder. Experimental measurements and simulations results are presented in Figures 4 and 5 . We can see that, at room temperature, there are very good agreements between simulations and measurements for a relative permeablity of the cylinder equal to 200 .

re 4.

resistance $R_{\mathrm{S}}$ in $f$ the inductor $d$ by the coil and rromagnetic ler

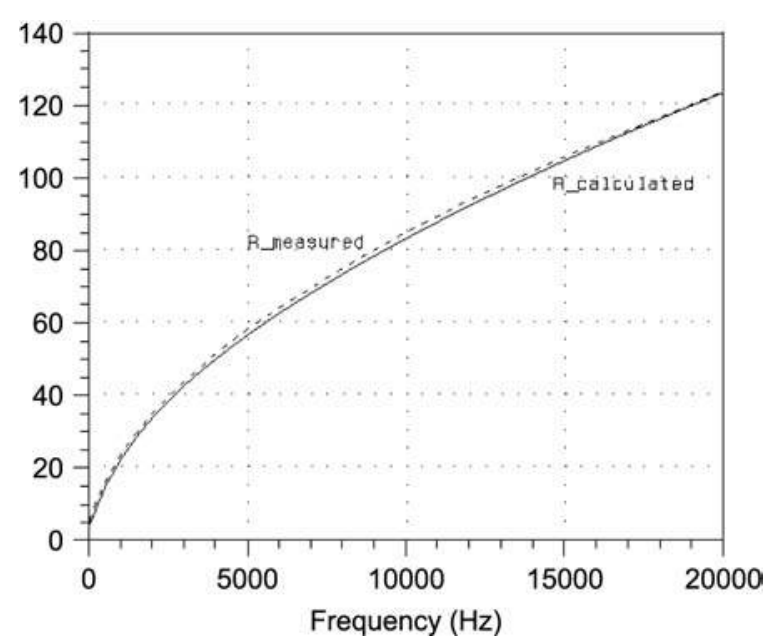




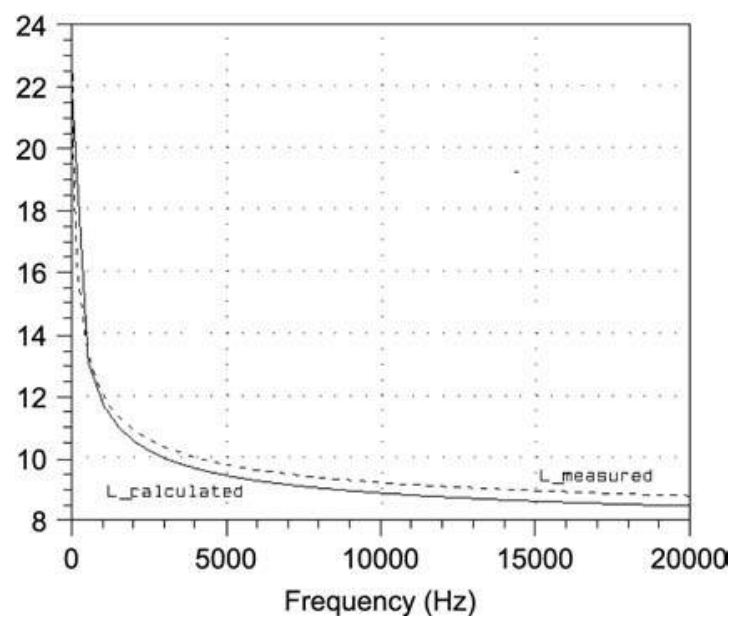

Figur Series inductance $L$ $\mu H$ of the indu formed by the coil the ferromagn cylir

Then, we studied the feeding of this device by a resonant inverter. Again the studies were made by simulations and experiments. For the simulations, we used MagCvs which solves the system of differential equations (10) by the backward Euler method and takes into account the feedback control of the inverter.

In the induction heating device supplied by a resonant inverter considered here, a capacitor is connected in parallel with the inductor (Figure 6). The switching frequency of the inverter should be tuned at the natural frequency of the parallel resonant circuit formed by the inductor and the capacitor. To achieve this goal, the gating signals of the four transistors forming the inverter are elaborated from the measurement of the voltage across the capacitor by the feedback operation shown in Figure 7. This operation is taken into account during simulation by the algorithm of control loops presented in Figure 2. One of the main difficulty is to estimate the values of the conductivity and the relative permeability of the ferromagnetic cylinder because these parameters vary during the heating of the cylinder. The coil is maintained at a temperature

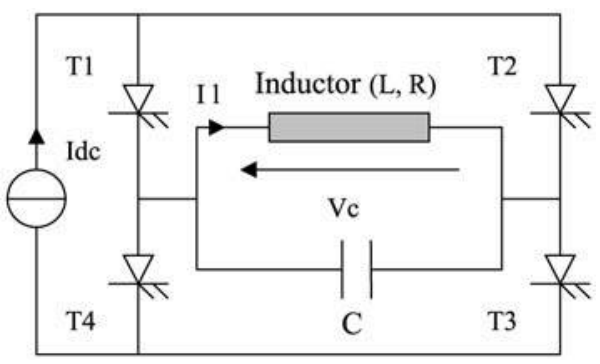

Figur Full bridge cur: inve 
of $30^{\circ} \mathrm{C}$. During experiments, the current source is fixed at a relatively low value ( $I \mathrm{~d} c=20 \mathrm{~A}$ ) to maintain the temperature of the cylinder under the Curie temperature of steel and the magnetic saturation of the cylinder as low as possible.

The simulation and experimental results are shown in Figure 8. One of the sine wave represents the voltage $V_{\mathrm{C}}$ across the capacitor and the square wave is the current $I_{\text {Load }}$ in the whole load formed by the inductor and the capacitor. $I_{1}$ is the current in the inductor alone. The measured resonant frequency and the amplitude of $V_{c}$ are respectively $15.9 \mathrm{kHz}$ and $216 \mathrm{~V}$ while the simulation gives us $16.1 \mathrm{kHz}$ and $185 \mathrm{~V}$. We tried several values of the conductivity and the permeability of the cylinder. We obtain the best agreements between experimental measurements and simulations results for a conductivity of $3.9 \times$ $10^{6} \mathrm{~S} / \mathrm{m}$ and a relative permeability of 100 . The real values of these parameters are very difficult to evaluate during heating operation. We can see here the double advantages brought by the method presented here: we do not need to calculate the equivalent impedance of the inductor, which depends on the frequency operation, nor to define, at the beginning of the simulation, the switching signals of PECs.

Figure 9 shows, in a 3D representation, the distribution of the current density inside the coils of the inductor and the hollow cylinder. The two representations are separated to make them clear and understandable. The mesh (Figure 3 ) is represented in the plane and the value of the current density on each node is reported in the $z$ axis. The current densities are calculated when the current in the inductor is equal to its amplitude at the resonance frequency $(16.1 \mathrm{kHz})$. The maximum value of the current density is $45 \mathrm{~A} / \mathrm{mm}^{2}$ inside the cylinder and $23.5 \mathrm{~A} / \mathrm{mm}^{2}$ inside the inductor.

\section{Conclusion}

In this paper, a method taking into account the feedback control in a time stepped coupled field circuit model is presented. This method is based on the formalism of sampling mode. It allows the simulation of complex system involving a strong interactions between power converters associated with

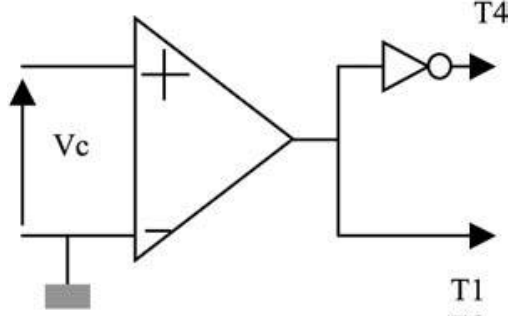




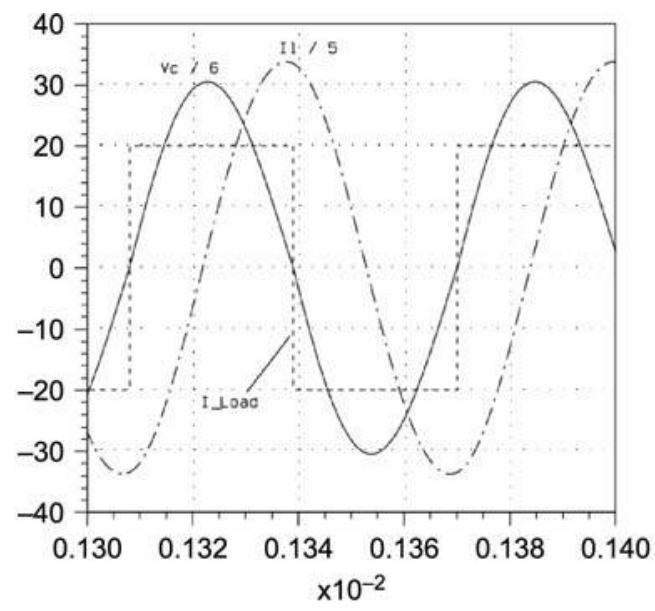

(a)

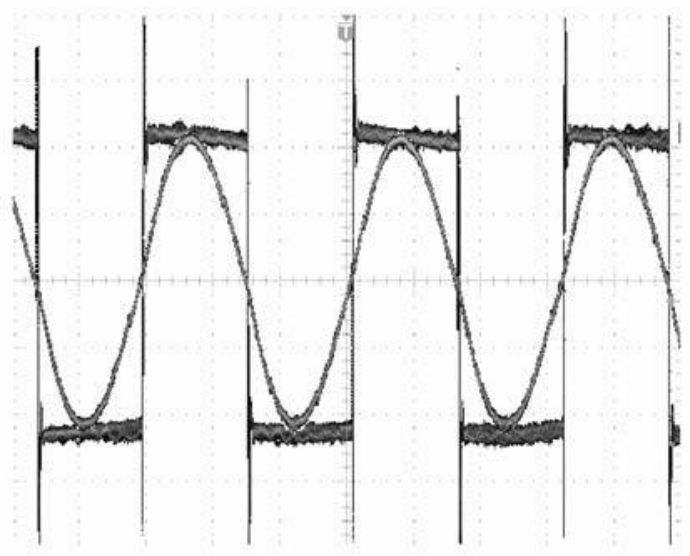

(b)

Figur (a) Voltage drop $V$ capacitor, total cur: $I_{\text {Load }}$ and the curre in the inductor obtai by simulations, (b) $I$ and $V_{\mathrm{c}}$ obtainec measurements $(10 \mathrm{~A}$ $100 \mathrm{~V} / \mathrm{div}$ and $20 \mu \mathrm{s} /$

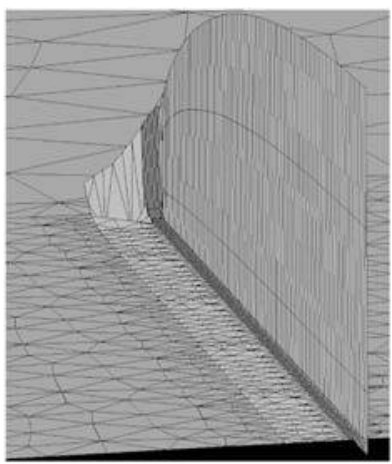

(a)

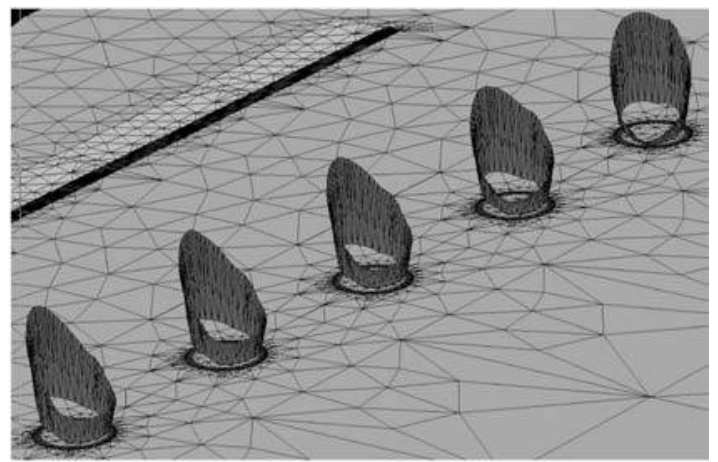

(b)
Figur

Three dimensic representation of distribution (at $16.1 \mathrm{k}$ (a) of the opposite of current density (inside the hol cylinder, (b) of current density $\left(J_{z}\right)$ in the coil of the indu 
electromagnetic devices and their controls. An application related to the induction heating where eddy currents cannot be neglected is presented. Saturation of ferromagnetic material can be taken into account as well. The comparison of simulation and experimental results offer interesting perspectives in industrial applications of this method. It also shows that the main difficulty is to estimate the physical parameters like conductivity and permeability in function of the operating temperature of the device.

\section{References}

Charpentier, J.F., Lefèvre, Y. and Piquet, H. (1997), "Une méthode générale pour modéliser les convertisseurs statiques associés à des dispositifs magnétiques”, J. Phys. III, pp. 2225-37 France 7.

Kuo-Peng, P. et al. (1998), "Analysis of a combined converter electromagnetic device by taking into account its control loop”, IEEE Trans. Energy Conversion.

Lombard, P. and Meunier, G. (1993), "Couplage des équations électriques et magnétiques”, J. Phys. III, pp. 397-412 France 3.

Louisnard, O., Meynard, T. and Piquet, H. (1992), "Simulation program for the design of static power converter", PCIM-Nuremberg.

Piriou, F. and Razek, A. (1993), "Finite element analysis in electromagnetic systems accounting for electric circuit", IEEE Trans. Magn., Vol. 29, pp. 1669-75.

Sadowski, N. et al. (1993), "Finite element simulation of electrical motors fed by current inverters", IEEE Trans. Magn., Vol. 29 No. 2, pp. 1683-8.

Tsukerman, I.A. et al. (1993), "Coupled field circuit problems: trends and accomplishments", IEEE Trans. On Magnetics, Vol. 29 No. 2, pp. 1701-4. 


\section{This article has been cited by:}

1. Professor Raffaele Martone and Professor Alessandro FormisanoG.B. KumbharDepartment of Electrical Engineering, Indian Institute of Technology - Bombay, Mumbai, India S.V. KulkarniDepartment of Electrical Engineering, Indian Institute of Technology - Bombay, Mumbai, India R. EscarelaPerezDepartamento de Energia, Universidad Autonoma Metropolitana, Mexico E. CamperoLittlewoodDepartamento de Energia, Universidad Autonoma Metropolitana, Mexico. 2007. Applications of coupled field formulations to electrical machinery. COMPEL - The international journal for computation and mathematics in electrical and electronic engineering 26:2, 489-523. [Abstract] [Full Text] [PDF] 